\title{
Association Between Olfactory Function and Asthma in Adults
}

This article was published in the following Dove Press journal:

Journal of Asthma and Allergy

\author{
Hyo-In Rhyou (iD \\ Woo Yong $\mathrm{Bae}^{2}$ \\ Young-Hee Nam (1D) \\ 'Department of Internal Medicine, \\ College of Medicine, Dong-A University, \\ Busan, Korea; ${ }^{2}$ Department of \\ Otorhinolaryngology-Head and Neck \\ Surgery, Dong-A University, Busan, Korea
}

Purpose: Chronic rhinosinusitis (CRS) and allergic rhinitis (AR) are common asthmaassociated upper airway diseases. Olfactory dysfunction, a common symptom among these patients, is an increasingly recognized condition that is associated with a reduced quality of life and major health outcomes. However, there are few studies on the association between olfactory function and asthma. We investigated the relationship between asthma and olfactory function.

Patients and Methods: A total of 146 patients with asthma aged $>18$ years were retrospectively analyzed from August 2019 to February 2020. Olfactory function was assessed using the Sniffin' stick test or the YSK olfactory function test. We compared the clinical parameters of patients with olfactory dysfunction and patients with normosmia.

Results: Of the total participants, 68 (46.6\%) showed olfactory dysfunction (hyposmia, $\mathrm{n}=31$; anosmia, $\mathrm{n}=37$ ). The patients with olfactory dysfunction were older, had longer durations of asthma, and a higher proportion of those with poor general health, CRS, and nasal polyps compared to patients with normosmia. However, there were no significant differences in the socioeconomic status, lung function, asthma severity, and use of inhaled corticosteroids or intranasal steroids between the two groups. Age (odds ratio: $1.044,95 \%$ confidence interval: $1.009-1.081, P=0.012)$, poor general health $(3.304,1.231-8.863$, $P=0.018$ ), CRS (2.589, 1.155-5.804, $P=0.021)$, and nasal polyps (3.306, 1.1-9.94, $P=0.033)$ were significantly associated with olfactory dysfunction.

Conclusion: Olfactory dysfunction was quite frequently observed in adults with asthma. Age, poor general health, CRS, and nasal polyps were significantly associated with olfactory dysfunction.

Keywords: asthma, chronic rhinosinusitis, olfactory dysfunction

\section{Introduction}

Chronic rhinosinusitis (CRS) and allergic rhinitis (AR) are common asthmaassociated upper airway diseases that contribute substantially to poor asthma control and disease burden. ${ }^{1,2}$ Olfactory dysfunction, a common symptom among these patients, ${ }^{1}$ is not only considerably prevalent ${ }^{3,4}$ but also the most common chronic medical condition in the United States. ${ }^{5}$ The sense of smell is an important chemical warning system that detects various odors including unpleasant ones and those of hazardous substances. Moreover, it regulates food intake and triggers emotions and memories. ${ }^{6}$ Although olfactory dysfunction is not a life-threatening or highly comorbid condition, ${ }^{7}$ it is closely associated with a poor quality of life (QOL) and psychological state. ${ }^{8-12}$ Moreover, this condition is also highly associated with asthma control status. However, there are few studies on the association
Correspondence: Young-Hee Nam Department of Internal Medicine, College of Medicine, Dong-A University, 26 Daesingongwon-Ro, Seo-Gu, Busan, Korea

Tel $+825 \mathrm{I}-240-5860$

Fax +82-5I-242-5864

Email yhnam@dau.ac.kr
Journal of Asthma and Allergy 2021:14 309-316 
between olfactory function and asthma, and olfactory dysfunction is underestimated and overlooked by patients and doctors. ${ }^{13,14}$

The aim of the present study was to investigate olfactory function in patients with asthma and evaluate the relationship between asthma and olfactory function.

\section{Patients and Methods \\ Participants and Study Design}

This study was conducted at Dong-A University Hospital from August 2019 to February 2020. A total of 146 adult patients with asthma aged $>18$ years were included, and the diagnosis of asthma was based on clinical symptoms, spirometry with bronchodilator test, and airway hyperresponsiveness to methacholine or mannitol. We compared the clinical parameters of the patients with and without olfactory dysfunction. This study complied with the Declaration of Helsinki and was approved by the institutional review board of Dong-A University Hospital, Busan, South Korea (DAUHIRB-19-175). Informed consent was obtained from all the participants.

\section{Assessment}

Olfactory function was assessed using the Korean version of the Sniffin' stick test (KVSS II; Burghart Company, Wedel, Germany) or YSK olfactory function test (YOF test; Kimex Co., Suwon, Korea). Accordingly, the threshold, discrimination, and identification scores were measured, and the sum of these three scores was defined as the olfactory score (range: 0-48 for KVSS II, 1-36 for YOF). The severity of olfactory dysfunction was classified as follows based on previous studies: ${ }^{15,16}$ anosmia, $\leq 20$ on KVSS II or $\leq 14.5$ on YOF; hyposmia, $>20$ on KVSS II or $>14.5$ on YOF; normosmia, $>27$ on KVSS II or $>21$ on YOF.

The KVSS test, developed in 1999, is a modified type of Sniffin' stick test widely used in Korea; whereas, the YOF test is a recently developed olfactory function test that uses odorants that are culturally familiar to Koreans, and showed an equivalent validity with KVSS II. ${ }^{16}$ Olfactory dysfunction was determined as anosmia or hyposmia using these two olfactory function tests in the present study. The olfactory function tests were performed in patients who experienced acute asthma exacerbations requiring systemic steroid treatment for more than 3 days or in those who received systemic steroids for other medical conditions related to sinonasal diseases and were assessed after 12 weeks.
The clinical and demographic characteristics of the study participants were analyzed by reviewing the electronic medical records used in our previous study. ${ }^{17}$ A self-administered questionnaire was administered to determine the general health and educational status, problems with the sense of smell, visual analog scale score for olfactory ability (range 0-10: $0=$ anosmia; $10=$ normal sense of smell), duration of olfactory impairment, and any history of treatment with sinusitis or olfactory dysfunction (Table S1). The diagnosis of CRS was based on patient history and the results of clinical examination, nasal endoscopy, and sinus computed tomography. Atopy was determined via an allergen skin prick test or by ImmunoCAP (Thermo Fisher Scientific/Phadia, Uppsala, Sweden). The tests were considered positive when a mean wheal diameter $\geq 3 \mathrm{~mm}$ was obtained or serum-specific immunoglobulin $\mathrm{E}$ levels against common inhalant allergens were detected at levels $\geq 0.35 \mathrm{kU} / \mathrm{L}$. Severe asthma was defined as three or more exacerbations requiring systemic steroid treatment for more than 3 days despite the administration of the Global Initiative for Asthma step 4 or 5 therapy in the past 12 months or any severe life-threatening asthma attack as defined in a previous study. ${ }^{17}$

\section{Statistical Analysis}

Categorical variables were presented as frequencies and proportions, and continuous variables were presented as mean \pm standard deviation and absolute numbers. To assess for statistical significance, Pearson's chi-squared test was used for categorical variables. The Student's $t$-test or Mann-Whitney $U$-test was used for continuous variables and analysis of variance with Scheffé's or Dunnett's post hoc test for the continuous variables. The correlation between the YOF scores and asthma duration or lung function were calculated using the Pearson coefficient and adjusted for age. Logistic regression analysis was performed to estimate the association between clinical parameters and olfactory dysfunction. Statistical analyses were performed using SPSS 18.0 (SPSS Inc., Chicago, IL, USA). A $P$ - value of $<0.05$ was considered statistically significant.

\section{Results}

\section{Demographic and Clinical Characteristics of the Participants}

A total of 146 participants performed olfactory function tests (KVSS II, $\mathrm{n}=25$; YOF, $\mathrm{n}=121$ ), and 68 (46.6\%) had olfactory dysfunction (anosmia, $\mathrm{n}=37$; hyposmia, $\mathrm{n}=31$ ). 
The distribution of olfactory function in the patients is shown in Figure 1. The patients with olfactory dysfunction were older $(62.78 \pm 13.65$ years vs $56.18 \pm 14.33$ years, $P<0.005)$ and had a higher proportion of those with poor general health $(85.3 \%$ vs $70.5 \%, P=0.033)$ compared to the patients with normosmia (Table 1). The proportions of patients with CRS $(66.2 \%$ vs $42.3 \%, P=0.004)$ and nasal polyps $(26.5 \%$ vs $12.8 \%, P=0.037)$ were significantly higher in patients with olfactory dysfunction than in those with normosmia. There were no significant differences in income and educational status, body mass index, and smoking status between the two groups. The mean duration of asthma was longer (116.43 \pm 90.54 months, vs $87.7 \pm 65.61$ months, $P=0.033)$, and life-threatening asthma exacerbation was more frequent $(10.3 \%$ vs $0.0 \%$, $P=0.004)$ in the olfactory dysfunction group than in the normosmic group; however, there were no significant differences in the lung function, asthma severity, use of inhaled corticosteroids or intranasal steroids, and atopy between the two groups. Clinical characteristics of the study participants were compared according to the severity of olfactory dysfunction (normosmia, $\mathrm{n}=78$; hyposmia, $\mathrm{n}=31$; anosmia, $\mathrm{n}=37$ ) (Table 2). There were significant differences in age $(56.18 \pm 14.33$ years in normosmia, $66.52 \pm 11.02$ years in hyposmia, $59.65 \pm 14.94$ years in anosmia, $P=0.003)$, asthma duration $(87.7 \pm 65.61$ months vs $98.29 \pm 88.14$ months vs $131.62 \pm 90.9$ months, $P=0.020)$, CRS $(42.3 \%$ vs $51.6 \%$ vs $78.4 \%, P=0.001)$, and nasal polyps $(12.8 \%$ vs $16.1 \%$ vs $35.1 \%, P=0.016)$ according to severity of olfactory dysfunction.
There was agreement between the results of the olfactory function test and those of the questionnaire survey on problems with the sense of smell in $68.5 \%$ of the participants (normosmia group, 64.1\%; olfactory dysfunction group, 73.5\%). Among patients with olfactory dysfunction, $26.5 \%$ reported having no problems with sense of smell, and $35.9 \%$ of the normosmia group reported that they had an impaired sense of smell (Table 1). There was no difference in the duration of olfactory impairment between the two groups $(78.6 \pm 67.71$ months vs 76.67 \pm 109.39 months, $P=0.941)$. However, the visual analog scale score for olfactory ability was significantly lower in the olfactory dysfunction group than in the normosmic group (5.25 \pm 1.37 vs $3.59 \pm 2.68, P=0.001)$.

In correlation analysis, the YOF scores were negatively correlated with asthma duration $(\mathrm{r}=-0.174, P=0.056)$, and negatively correlated with lung function (pre-FEV1 (L), $\mathrm{r}=0.145, P=0.111$; pre-FEV1 (\%), r=0.162, $P=0.076$; postFEV1 (L), $\mathrm{r}=0.116, P=0.205$; post-FEV1 (\%), $\mathrm{r}=0.152$, $P=0.097$ ) (Table 3 ). But, there was no statistically significance was observed after the age adjustment.

\section{Risk Factors for Olfactory Dysfunction by Logistic Regression Analysis}

Age (odds ratio: 1.044, 95\% confidence interval: 1.009-1.081, $P=0.012)$, poor general health $(3.304,1 .-$ 231-8.863, $\quad P=0.018), \quad \mathrm{CRS} \quad(2.589, \quad 1.155-5.804$, $P=0.021)$, and nasal polyps $(3.306,1.1-9.94, P=0.033)$ were significantly associated with olfactory dysfunction in both univariate and multivariate regression analyses;

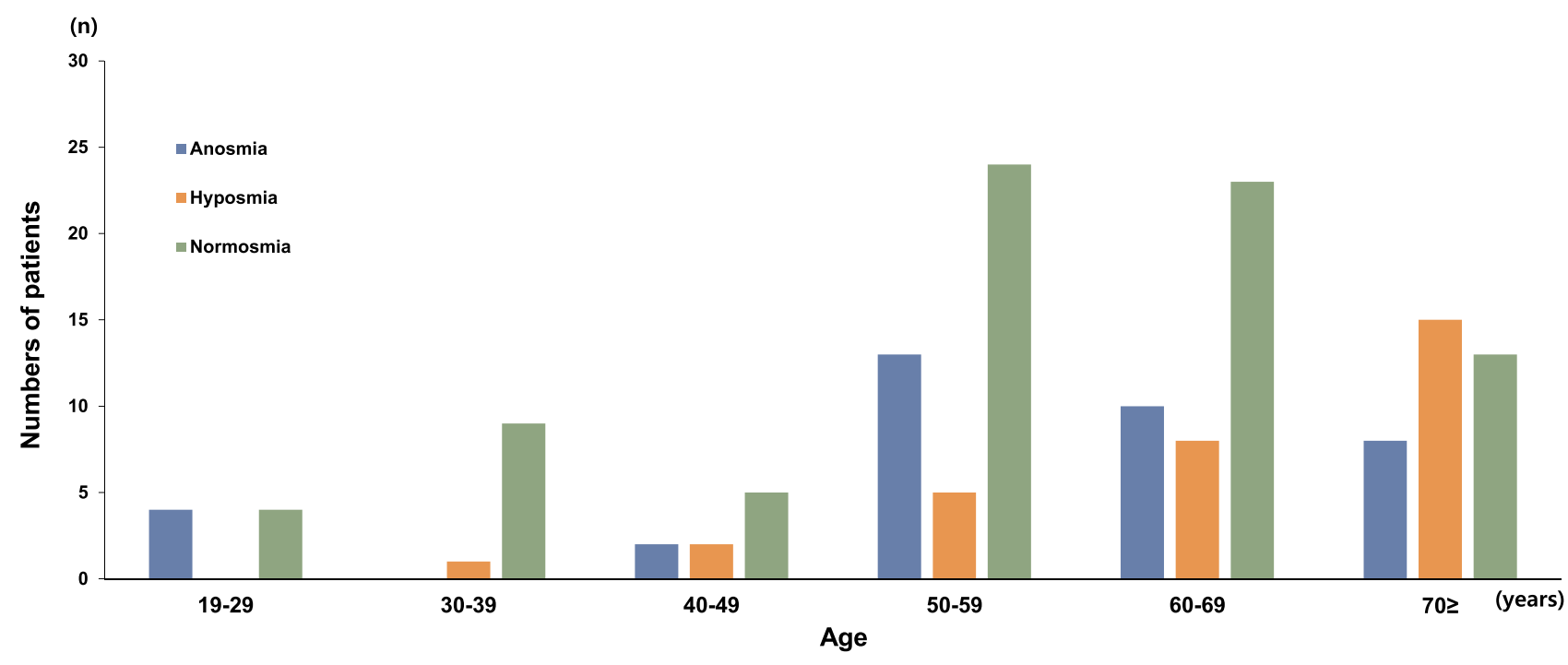

Figure I Age-related distribution of olfactory function in the study participants. 
Table I Clinical Characteristics of the Total Study Participants

\begin{tabular}{|c|c|c|c|c|}
\hline & Total & Normosmia & $\begin{array}{l}\text { Olfactory } \\
\text { Dysfunction }\end{array}$ & $P$-value \\
\hline & $n=146(\%)$ & $n=78(\%)$ & $n=68(\%)$ & \\
\hline Age*, years & $59.25 \pm 14.35$ & $56.18 \pm 14.33$ & $62.78 \pm 13.65$ & 0.005 \\
\hline Female & $80(54.8)$ & $46(59)$ & $34(50)$ & 0.277 \\
\hline Body mass index*, $\mathrm{kg} / \mathrm{m}^{2}$ & $23.9 \pm 3.87$ & $24.26 \pm 4.39$ & $23.5 \pm 3.19$ & 0.235 \\
\hline \multicolumn{5}{|l|}{ Smoking status } \\
\hline Never-smoker & $92(63)$ & $50(64.1)$ & $42(61.8)$ & 0.915 \\
\hline E-smoker & $24(16.4)$ & $13(16.7)$ & II (I6.2) & \\
\hline Current smoker & $30(20.5)$ & $15(19.2)$ & $15(22.1)$ & \\
\hline \multicolumn{5}{|l|}{ Household income } \\
\hline Low & $19(13)$ & $9(11.5)$ & $10(14.7)$ & 0.57 \\
\hline Middle-high & $127(87)$ & $69(88.5)$ & $58(85.3)$ & \\
\hline \multicolumn{5}{|l|}{ Education } \\
\hline$<$ High school & $85(58.2)$ & $50(64.1)$ & $35(51.5)$ & 0.123 \\
\hline >High school graduate & $61(41.8)$ & $28(35.9)$ & $33(48.5)$ & \\
\hline \multicolumn{5}{|l|}{ General health } \\
\hline Fair, poor, good & II3 (77.4) & $55(70.5)$ & $58(85.3)$ & 0.033 \\
\hline Excellent, very good & $33(22.6)$ & $23(29.5)$ & $10(14.7)$ & \\
\hline Allergic rhinitis & $73(50)$ & $37(47.4)$ & $36(52.9)$ & 0.507 \\
\hline Chronic rhinosinusitis & $78(53.4)$ & $33(42.3)$ & $45(66.2)$ & 0.004 \\
\hline Nasal polyps & $28(19.2)$ & $10(12.8)$ & $18(26.5)$ & 0.037 \\
\hline Asthma duration*, months & $101.17 \pm 79.33$ & $87.7 \pm 65.61$ & $116.43 \pm 90.54$ & 0.033 \\
\hline Severe asthma & $32(21.9)$ & $19(24.4)$ & $13(19.1)$ & 0.445 \\
\hline Life-threatening asthma exacerbation & $7(4.8)$ & $0(0)$ & $7(10.3)$ & 0.004 \\
\hline $\mathrm{FEV}_{1} *, \%$ & $78.0 \pm 19.76$ & $75.91 \pm 20.23$ & $73.97 \pm 19.3$ & 0.556 \\
\hline Inhaled corticosteroid use & $122(84.1)$ & $62(80.5)$ & $60(88.2)$ & 0.204 \\
\hline Intranasal steroid use & $45(30.8)$ & $26(33.3)$ & $19(27.9)$ & 0.482 \\
\hline Atopy & $76(52.1)$ & $40(51.3)$ & $36(52.9)$ & 0.841 \\
\hline \multicolumn{5}{|c|}{$\begin{array}{l}\text { Agreement between a questionnaire on olfaction and olfactory function } \\
\text { tests }\end{array}$} \\
\hline Yes & $100(68.5)$ & $50(64.1)$ & $50(73.5)$ & 0.221 \\
\hline No & $46(31.5)$ & $28(35.9)$ & $18(26.5)$ & \\
\hline
\end{tabular}

Note: *Data presented as mean \pm standard deviation.

Abbreviation: $\mathrm{FEV}_{\mathrm{l}}$, forced expiratory volume in I second.

however, asthma duration was associated with olfactory dysfunction only in the univariate analysis (Table 4). Income and educational status, the use of inhaled corticosteroids or intranasal steroids, lung function, and severe asthma were not associated with olfactory dysfunction.

\section{Discussion}

Olfactory dysfunction is increasingly recognized, and its prevalence and incidence vary significantly according to the study population, definitions of impairment, and assessment techniques. ${ }^{18}$ In a random sample of 1312 adults, $18 \%$ were revealed to have olfactory dysfunction 
Table 2 Clinical Characteristics of the Study Participants According to Severity of Olfactory Dysfunction

\begin{tabular}{|l|c|c|c|c|}
\hline Characteristics & Normosmia n=78 (\%) & Hyposmia n=31 (\%) & Anosmia n=37 (\%) & P-value \\
\hline Age*, years & $56.18 \pm 14.33$ & $66.52 \pm 11.02^{\pi}$ & $59.65 \pm 14.94$ & 0.003 \\
Asthma duration*, months & $87.7 \pm 65.61$ & $98.29 \pm 88.14$ & $131.62 \pm 90.9^{*}$ & 0.020 \\
Chronic rhinosinusitis & $33(42.3)$ & $16(51.6)$ & $29(78.4)$ & 0.001 \\
Nasal polyps & $10(12.8)$ & $5(16.1)$ & $13(35.1)$ & 0.016 \\
\hline
\end{tabular}

Notes: *Data presented as mean \pm standard deviation. "Post hoc analysis: $P=0.003$, hyposmia vs normosmia. ${ }^{*}$ Post hoc analysis: $P=0.021$, anosmia vs normosmia.

Table 3 Correlation Between the YOF Scores and Asthma Duration or Lung Function in Study Participants

\begin{tabular}{|l|c|c|c|c|}
\hline Characteristics & $\mathbf{r}$ & $\boldsymbol{P}$-value & $\mathbf{r}^{*}$ & $\boldsymbol{P}$-value \\
\hline Asthma duration, month & -0.174 & 0.056 & -0.152 & 0.097 \\
Prebronchodilator $\mathrm{FEV}_{1}, \mathrm{~L}$ & 0.145 & 0.111 & 0.079 & 0.391 \\
Prebronchodilator $\mathrm{FEV}_{1}, \%$ & 0.162 & 0.076 & 0.125 & 0.174 \\
Postbronchodilator $\mathrm{FEV}_{1}, \mathrm{~L}$ & 0.116 & 0.205 & 0.041 & 0.658 \\
Postbronchodilator $\mathrm{FEV}_{1}, \%$ & 0.152 & 0.097 & 0.112 & 0.222 \\
\hline
\end{tabular}

Note: $r^{*}$ adjusted for age.

Abbreviations: $\mathrm{FEV}_{1}$, forced expiratory volume in I second; YOF, YSK olfactory function.

using the Sniffin' sticks test. ${ }^{19}$ The prevalence of dysfunction based on the Scandinavian Odor Identification Test was $19.1 \%$ in 1387 adult participants. ${ }^{4}$ In the current study, $46.6 \%$ of the adult patients with asthma had olfactory dysfunctions. It was considerably higher than that in previous studies, even though the samples were based on the general population. There has been no study on the prevalence of olfactory dysfunction in patients with asthma. However, the presence of asthma was associated with a higher frequency of anosmia in the 68 patients with olfactory dysfunction $(60.0 \%$ vs $18.3 \% ; P<0.001),{ }^{8}$ and the prevalence of olfactory dysfunction was significantly higher than that in the patients without asthma (26\% vs $6 \%, P=0.001$ ) among the 145 adult patients with CRS. ${ }^{20}$

In the current study, the prevalence of olfactory dysfunction in patients with asthma and CRS was $56.5 \%$, and it was higher value than that of olfactory dysfunction in total study participants. However, the prevalence of olfactory dysfunction in patients with asthma without upper airway diseases (CRS or AR) was $15.8 \%$, which was similar to the prevalence of olfactory dysfunction in general population as in previous studies. ${ }^{4,19}$ Several underlying etiological conditions cause olfactory dysfunctions, in which CRS (or AR) is the main cause of olfactory loss due to sinonasal diseases. ${ }^{21-23}$ To date, there is no evidence of an association between asthma and olfactory dysfunction. Upper airway diseases such as CRS and rhinitis are commonly accompanied by asthma; therefore, we deduced that there would be a high prevalence of olfactory dysfunction in patients with asthma and a substantial association between these conditions. A high prevalence of olfactory dysfunction was observed in patients with asthma and CRS in the current study, and

Table 4 Risk Factors for Olfactory Dysfunction by Logistic Regression Analysis

\begin{tabular}{|c|c|c|c|c|}
\hline & Univariate & \multirow[t]{2}{*}{$P$-value } & Multivariate & \multirow[t]{2}{*}{$P$-value } \\
\hline & Odds Ratio (95\% Confidence Interval) & & Odds Ratio (95\% Confidence Interval) & \\
\hline Age, years & $1.035(1.01-1.062)$ & 0.007 & $1.044(1.009-1.08 I)$ & 0.012 \\
\hline Low income & $1.322(0.503-3.473)$ & 0.571 & $0.779(0.247-2.457)$ & 0.67 \\
\hline Low education & $1.684(0.867-3.269)$ & 0.124 & $1.18(0.471-2.954)$ & 0.724 \\
\hline $\begin{array}{l}\text { General health } \\
\text { (fair, poor, good) }\end{array}$ & $2.425(1.059-5.557)$ & 0.036 & $3.304(1.231-8.863)$ & 0.018 \\
\hline Chronic rhinosinusitis & $2.668(1.36-5.234)$ & 0.004 & $2.589(1.155-5.804)$ & 0.021 \\
\hline Nasal polyps & $2.448(I .04 I-5.756)$ & 0.04 & $3.306(1.1-9.94)$ & 0.033 \\
\hline Asthma duration, years & $1.005(1.0-1.009)$ & 0.033 & $1.001(0.996-1.006)$ & 0.651 \\
\hline $\mathrm{FEV}_{1}, \%$ & $0.995(0.979-1.012)$ & 0.995 & $1.004(0.984-1.024)$ & 0.708 \\
\hline Severe asthma & $0.734(0.331-1.626)$ & 0.734 & $0.574(0.22-1.499)$ & 0.257 \\
\hline Inhaled corticosteroid use & $1.815(0.717-4.592)$ & 0209 & $1.752(0.547-5.609)$ & 0.345 \\
\hline Intranasal steroid use & $0.776(0.382-1.575)$ & 0.482 & $0.556(0.231-1.333)$ & 0.188 \\
\hline
\end{tabular}

Abbreviation: $\mathrm{FEV}_{\mathrm{l}}$, forced expiratory volume in I second. 
this supports the results of a previous study that showed that asthma was a risk factor for olfactory dysfunction in patients with CRS. ${ }^{8,24}$ In clinical practice, assessing the upper airway diseases in asthmatics who altered olfactory function can be helpful in the management of asthma, as these comorbidities can have a significant negative impact on asthma control. Additionally, a significant improvement in CRS with nasal polyp symptoms as well as control of asthma and lung function was observed after 1 month of mepolizumab treatment and was maintained until 6 months in a real-life population of severe asthmatics. ${ }^{25}$ Systemic inflammations in the upper and lower respiratory tracts caused olfactory dysfunction, ${ }^{26}$ and it might be associated with asthma-related risk for olfactory dysfunction in patients with CRS. Further studies are needed to investigate the pathophysiology of olfactory dysfunction in patients with upper airway diseases and asthma.

This study found age, poor general health, CRS and nasal polyps were associated with olfactory dysfunction in patients with asthma. Moreover, the duration of asthma, age, CRS, and nasal polyps were related to the severity of olfactory dysfunction. The prevalence of olfactory dysfunction increased with age. ${ }^{3,19,27}$ Atrophy of the olfactory bulb and $\operatorname{tract}^{28}$ and volume loss in the temporal lobe, which is important for olfactory processing, ${ }^{29}$ are associated with age. Olfactory mucosa may be replaced with respiratory epithelium as a result of long-lasting injuries to it. ${ }^{30}$ These factors may lead to age-related olfactory dysfunction. Olfactoryimpaired patients had more difficulties in daily-life activities and a reduced QOL, and an increased severity of olfactory dysfunction was associated with a poorer QOL and a higher degree of depression and anxiety. ${ }^{8,11,31-33}$ CRS was associated with conductive and sensorineural olfactory dysfunctions, including mechanical obstruction of odorant transmission in the olfactory cleft due to mucosal inflammation. ${ }^{34,35}$ Some studies have reported negative effects of a lower socioeconomic status ${ }^{8,36}$ and smoking ${ }^{37}$ on olfactory function; however, these were not associated with olfactory function in the current study.

In the present study, YOF scores were not significantly correlated with asthma duration and lung function. However, a history of life-threatening asthma exacerbation was significantly more frequent in the olfactory dysfunction group than in the normosmic group, although asthma severity was not related to olfactory dysfunction. Olfactory dysfunction could be assumed to be related to asthma control. As only 7 cases of life-threatening asthma exacerbation were reported, largescale research will be required in the future.
There was a large discrepancy between the results of the subjective questionnaire survey on olfactory ability and those of the objective olfactory function test in the current study. In patients with hyposmia, $26.5 \%$ reported no loss of the sense of smell. On the contrary, $35.9 \%$ of the patients with normosmia reported loss of the sense of smell. However, selfreported olfactory function has shown low sensitivity in previous studies. ${ }^{4,36}$ Many people with impaired senses of smell are unaware of their olfactory problems. Alternatively, many people with a normal sense of smell might misunderstand their olfactory function. Depending on the situation, it might cause either delayed treatment or unnecessary medical care. Thereafter, physicians should seek to evaluate olfactory function using objective tests in patients with asthma.

There were several limitations of the present study. First, this was a cross-sectional study. Therefore, we could not clarify the causal relationship between olfactory dysfunction and asthma. As CRS is the main cause of olfactory dysfunction and is often accompanied by asthma, ${ }^{1,2}$ we assumed that a considerable number of patients with asthma would suffer from a decreased sense of smell. However, it cannot be concluded whether asthma is the cause of olfactory dysfunction; therefore, further research is needed. Second, as the study population was heterogeneous, the participants had varying durations and degrees of severity of asthma and comorbid upper-airway diseases. However, the strength of this study is that it confirmed olfactory function through an objective test. Third, two test methods (YOF and KVSS II) were used to evaluate olfactory function. The YOF test result was only analyzed for evaluation of correlation. In the present study, KVSS II test was substituted with YOF test owing to the discontinuation of production of the KVSS II test kit. However, the majority of study participants performed the YOF test, with equivalent diagnostic efficacy as KVSS II. ${ }^{16}$

\section{Conclusion}

We found that the rate of occurrence of olfactory dysfunction was significant in patients with asthma, and age, poor general health, CRS and nasal polyps were associated with olfactory dysfunction. However, additional verification is needed to determine the relationship between olfactory function and asthma, and it is necessary for physicians to pay attention to olfactory function in patients with asthma. 


\section{Abbreviations}

$\mathrm{AR}$, allergic rhinitis; CRS, chronic rhinosinusitis; $\mathrm{FEV}_{1}$, forced expiratory volume in 1 second; KVSS, Korean version of the Sniffin' stick test; QOL, quality of life; YOF, YSK olfactory function.

\section{Acknowledgments}

There are no financial or other issues that might confer a conflict of interest. The abstract of this paper was presented in American Academy of Allergy Asthma \& Immunology 2021 Virtual Annual Meeting as an abstract presentation with interim findings. The poster's abstract was published in "Poster Abstracts" in J Allergy Clin Immunol 2021 [https://doi.org/10.1016/j.jaci.2020.12.196].

\section{Funding}

This work was supported by the Dong-A University research fund.

\section{Disclosure}

The authors report no conflicts of interest in this work.

\section{References}

1. Feng CH, Miller MD, Simon RA. The united allergic airway: connections between allergic rhinitis, asthma, and chronic sinusitis. $\mathrm{Am}$ J Rhinol Allergy. 2012;26(3):187-190. doi:10.2500/ajra.2012.26.3762

2. Tay TR, Hew M. Comorbid "treatable traits" in difficult asthma: current evidence and clinical evaluation. Allergy. 2018;73 (7):1369-1382. doi:10.1111/all.13370

3. Lee WH, Wee JH, Kim DK, et al. Prevalence of subjective olfactory dysfunction and its risk factors: Korean national health and nutrition examination survey. PLoS One. 2013;8(5):e62725. doi:10.1371/journal.pone. 0062725

4. Brämerson A, Johansson L, Ek L, Nordin S, Bende M. Prevalence of olfactory dysfunction: the skövde population-based study. Laryngoscope. 2004;114(4):733-737. doi:10.1097/00005537200404000-00026

5. Vento SI, Simola M, Ertama LO, Malmberg CH. Sense of smell in long-standing nasal polyposis. Am J Rhinol. 2001;15(3):159-163. doi:10.2500/105065801779954229

6. Wang L, Walker VE, Sardi H, Fraser C, Jacob TJC. The correlation between physiological and psychological responses to odour stimulation in human subjects. Clin Neurophysiol. 2002;113(4):542-551. doi:10.1016/S1388-2457(02)00029-9

7. Toller SV. Assessing the impact of anosmia: review of a questionnaire's findings. Chem Senses. 1999;24(6):705-712. doi:10.1093/chemse/24.6.705

8. Katotomichelakis M, Simopoulos E, Zhang N, et al. Olfactory dysfunction and asthma as risk factors for poor quality of life in upper airway diseases. Am J Rhinol Allergy. 2013;27(4):293-298. doi:10.2500/ajra.2013.27.3903

9. Seo HS, Jeon KJ, Hummel T, Min BC. Influences of olfactory impairment on depression, cognitive performance, and quality of life in Korean elderly. Eur Arch Otorhinolaryngol. 2009;266 (11):1739-1745. doi:10.1007/s00405-009-1001-0
10. Nordin S, Blomqvist EH, Olsson P, Stjärne P, Ehnhage A; NAF2S2 Study Group. Effects of smell loss on daily life and adopted coping strategies in patients with nasal polyposis with asthma. Acta Otolaryngol. 2011;131(8):826-832. doi:10.3109/ 00016489.2010 .539625

11. Miwa T, Furukawa M, Tsukatani T, Costanzo RM, DiNardo LJ, Reiter ER. Impact of olfactory impairment on quality of life and disability. Arch Otolaryngol Head Neck Surg. 2001;127(5):497-503. doi:10.1001/archotol.127.5.497

12. Smeets MAM, Veldhuizen MG, Galle S, et al. Sense of smell disorder and health-related quality of life. Rehabil Psychol. 2009;54 (4):404-412. doi:10.1037/a0017502

13. Welge-Luessen A, Hummel T, Stojan T, Wolfensberger M. What is the correlation between ratings and measures of olfactory function in patients with olfactory loss? Am J Rhinol. 2005;19(6):567-571. doi:10.1177/194589240501900606

14. Hu B, Han D, Zhang L, et al. Olfactory event-related potential in patients with rhinosinusitis-induced olfactory dysfunction. Am J Rhinol Allergy. 2010;24(5):330-335. doi:10.2500/ajra.2010.24.3517

15. Cho JH, Jeong YS, Lee YJ, Hong SC, Yoon JH, Kim JK. The Korean version of the Sniffin' stick (KVSS) test and its validity in comparison with the cross-cultural smell identification test (CC-SIT). Auris Nasus Larynx. 2009;36(3):280-286. doi:10.1016/j.anl.2008.07.005

16. Ha JG, Kim J, Nam JS, et al. Development of a Korean culture-friendly olfactory function test and optimization of a diagnostic cutoff value. Clin Exp Otorhinolaryngol. 2020;13 (3):274-284. doi:10.21053/ceo.2020.00864

17. Rhyou HI, Nam YH. Association between cognitive function and asthma in adults. Ann Allergy Asthma Immunol. 2021;126(1):69-74. doi:10.1016/j.anai.2020.08.022

18. Yang J, Pinto JM. The epidemiology of olfactory disorders. Curr Otorhinolaryngol Rep. 2016;4(2):130-141. doi:10.1007/s40136-0160120-6

19. Vennemann MM, Hummel T, Berger K. The association between smoking and smell and taste impairment in the general population. $J$ Neurol. 2008;255(8):1121-1126. doi:10.1007/s00415-008-0807-9

20. Seybt MW, McMains KC, Kountakis SE. The prevalence and effect of asthma on adults with chronic rhinosinusitis. Ear Nose Throat J. 2007;86(7):409-411. doi:10.1177/014556130708600719

21. Hummel T, Whitcroft KL, Andrews P, et al. Position paper on olfactory dysfunction. Rhinology. 2016;56(1):1-30. doi:10.4193/ Rhin 16.248

22. Fokkens WJ, Lund VJ, Mullol J, et al. European position paper on rhinosinusitis and nasal polyps 2012. Rhinol Suppl. 2012;23:3 p preceding table of contents, 1-298.

23. Jung AA-O, Kim YA-O. Reversal of olfactory disturbance in allergic rhinitis related to OMP suppression by intranasal budesonide treatment. Allergy Asthma Immunol Res. 2020;12(1):110-124. doi:10.4168/aair.2020.12.1.110

24. Litvack JR, Fong K, Mace J, James KE, Smith TL. Predictors of olfactory dysfunction in patients with chronic rhinosinusitis. Laryngoscope. 2008;118(12):2225-2230. doi:10.1097/ MLG.0b013e318184e216

25. Cameli P, Bergantini L, d'Alessandro M, et al. A comprehensive evaluation of mepolizumab effectiveness in a real-life setting. Int Arch Allergy Immunol. 2020;181(8):606-612. doi:10.1159/000507996

26. Joe SA, Thakkar K. Chronic rhinosinusitis and asthma. Otolaryngol Clin North Am. 2008;41(2):297-309,vi. doi:10.1016/j. otc.2007.11.001

27. Bhattacharyya N, Kepnes LJ. Contemporary assessment of the prevalence of smell and taste problems in adults. Laryngoscope. 2015;125(5):1102-1106. doi:10.1002/lary.24999

28. Meisami E, Mikhail L, Baim D, Bhatnagar KP. Human olfactory bulb: aging of glomeruli and mitral cells and a search for the accessory olfactory bulb. Ann N Y Acad Sci. 1998;855:708-715. doi:10.1111/j.1749-6632.1998.tb10649.x 
29. Jernigan TL, Archibald SL, Fennema-Notestine C, et al. Effects of age on tissues and regions of the cerebrum and cerebellum. Neurobiol Aging. 2001;22(4):581-594. doi:10.1016/S0197-4580(01)00217-2

30. Nakashima T, Kimmelman CP, Snow JB Jr. Structure of human fetal and adult olfactory neuroepithelium. Arch Otolaryngol. 1984;110 (10):641-646. doi:10.1001/archotol.1984.00800360013003

31. Shu CH, Lee PO, Lan MY, Lee YL. Factors affecting the impact of olfactory loss on the quality of life and emotional coping ability. Rhinology. 2011;49(3):337-341. doi:10.4193/Rhino10.130

32. Frasnelli J, Hummel T. Olfactory dysfunction and daily life. Eur Arch Otorhinolaryngol. 2005;262(3):231-235. doi:10.1007/s00405-0040796-y

33. Neuland C, Bitter T, Marschner H, Gudziol H, Guntinas-Lichius O. Health-related and specific olfaction-related quality of life in patients with chronic functional anosmia or severe hyposmia. Laryngoscope. 2011;121(4):867-872. doi:10.1002/lary.21387
34. Alobid I, Benítez P, Cardelús S, et al. Oral plus nasal corticosteroids improve smell, nasal congestion, and inflammation in sino-nasal polyposis. Laryngoscope. 2014;124(1):50-56. doi:10.1002/ lary. 24330

35. Mullol J, Mariño-Sánchez F, Valls M, Alobid I, Marin C. The sense of smell in chronic rhinosinusitis. J Allergy Clin Immunol. 2020;145 (3):773-776. doi:10.1016/j.jaci.2020.01.024

36. Murphy CSC, Cruickshanks KJ, Klein BE, Klein R. Prevalence of olfactory impairment in older adults. JAMA. 2002;288 (18):2307-2312. doi:10.1001/jama.288.18.2307

37. Katotomichelakis M, Balatsouras D, Tripsianis G, et al. The effect of smoking on the olfactory function. Rhinology. 2007;45(4):273-280.

\section{Publish your work in this journal}

The Journal of Asthma and Allergy is an international, peer-reviewed open-access journal publishing original research, reports, editorials and commentaries on the following topics: Asthma; Pulmonary physiology; Asthma related clinical health; Clinical immunology and the immunological basis of disease; Pharmacological interventions and

Submit your manuscript here: https://www.dovepress.com/journal-of-asthma-and-allergy-journal new therapies. The manuscript management system is completely online and includes a very quick and fair peer-review system, which is all easy to use. Visit http://www.dovepress.com/testimonials.php to read real quotes from published authors. 